\title{
Total antioxidant capacity of honeybee haemolymph in relation to age and exposure to pesticide, and comparison to antioxidant capacity of seminal plasma
}

\author{
Mariola SŁowiŃSKA ${ }^{1}$, Joanna NyncA ${ }^{1}$, Jerzy WILDE ${ }^{2}$, Beata BĄK ${ }^{2}$, Maciej SiUdA ${ }^{2}$, \\ Andrzej CiereszKo ${ }^{1}$ \\ ${ }^{1}$ Department of Gamete and Embryo Biology, Institute of Animal Reproduction and Food Research, Polish Academy of \\ Sciences in Olsztyn, Tuwima 10, 10-748, Olsztyn, Poland \\ ${ }^{2}$ Department of Apiculture, Faculty of Animal Bioengineering, University of Warmia and Mazury in Olsztyn, Słoneczna \\ 48, 10-957, Olsztyn, Poland
}

Received 3 March 2015 - Revised 24 July 2015 - Accepted 10 September 2015

\begin{abstract}
Oxidative stress is defined as a disturbance in the balance between the production of reactive oxygen species and antioxidant defences. We measured total antioxidant capacity (TAC) in honeybee haemolymph and seminal plasma and analysed TAC of haemolymph in relation to age and exposure to pesticide. TAC of haemolymph increased with age of bees (1.18 vs $1.97 \mathrm{mM}$ of ( \pm )-6-hydroxy-2,5,7,8-tetramethylchromane-2-carboxylic acid (Trolox) for 1- and 30-day-old bees, respectively, $P \leq 0.05$ ). Exposure to imidacloprid (IMD) affected TAC of haemolymph of 1-day-old but not 30-day-old honeybees. TAC in haemolymph of 1-day-old bees was lower in treatments with the addition of 5 and $200 \mathrm{ppb}$ IMD (1.57-1.46 mM of Trolox in treated bees compared with $2.37 \mathrm{mM}$ of Trolox in controls; $P \leq 0.05$ ). In conclusion, antioxidant protection of honeybees seems to be related to age and may be disturbed by exposure to IMD. Older bees with higher antioxidant protection seem to be less susceptible to IMD toxicity. The toxic effect of pesticide seems to be particularly dangerous in early life stages of honeybees.
\end{abstract}

\section{Apis mellifera / total antioxidant capacity / haemolymph / ageing / pesticide}

\section{INTRODUCTION}

Oxidative stress is defined as a disturbance in the balance between the production of reactive oxygen species (ROS) and antioxidant defences. ROS generated in the process of oxidative metabolism can cause oxidation of proteins, RNAs, DNAs and peroxidation of membrane lipids (Michiels et al. 1994; Felton 1995; Felton and Summers 1995; Pardini 1995). The destructive reaction contributes to the processes of ageing, carcinogenesis and cell death. To protect against

Corresponding author: M. Słowińska, m.slowinska@pan.olsztyn.pl

Manuscript editor: Monique Gauthier the effects of oxidative stress, organisms have a variety of antioxidant enzymes and substances at their disposal to neutralise ROS.

The most important antioxidant enzymes identified in honeybee body fluids are superoxide dismutase (SOD), catalase (CAT), glutathione Stransferase (GST) and peroxidase (Weirich et al. 2002; Collins et al. 2004, 2006). To date, 39 genes coding ten groups of antioxidant proteins have been identified in the honeybee genome (Corona and Robinson 2006). Honeybees have lost gene coding for two important antioxidative enzymes, glutathione peroxidase and glutathione reductase. Beside antioxidant enzymes, the antioxidant system of insects is also composed of non-enzymatic components like glutathione, ascorbic acid, vitamin E, uric acid and thioredoxin (Summers and 
Felton 1993; Krishnan et al. 2009). Lowmolecular-weight antioxidants react with ROS in a less specific manner than enzymes and are therefore more universal and can interchangeably play a protective function (Colven and Pinnell 1996).

There are several components of the antioxidative system, and for this reason, it is difficult to measure the activity of individual antioxidants at the same time as evaluating antioxidant potential. Moreover, the measurement of all antioxidant enzymes in body fluids of individual honeybees is impossible due to the restricted volume of body fluids.

Total antioxidant capacity (TAC) is an alternative measurement of complete antioxidative status. The antioxidant assay is based on the formation of a ferryl myoglobin radical from myoglobin and hydrogen peroxide, which oxidises ABTS (2,2'-azino-bis(3-ethylbenzothiazoline-6-sulfonic acid)) to produce the radical cation $\mathrm{ABTS}^{+}$, a soluble green chromogen that can be determined spectrophotometrically. Antioxidants in the sample suppress production of this radical cation in a concentration-dependent manner. Recently, TAC has successfully been used to measure antioxidant levels of honeybee whole-body extracts after diet supplementation with vitamin C (Farjan et al. 2012) and when parasitised with Varroa destructor (Farjan et al. 2014). The value of TAC measurements using whole-body homogenate is limited because the specific origin of antioxidant protection cannot be defined. For diagnostic purposes, it would be more appropriate to measure TAC in body fluids of honeybees.

Quantitative measures of TAC appear to be a good indicator to evaluate the changes of oxidation status in honeybee body fluids caused by ageing and exposure to pesticides. In general, an increase in ROS generation and enhancement of antioxidant protection are associated with ageing and transition of worker bees to foraging (Johnson and Carey 2014). However, TAC has never been evaluated in haemolymph of honeybees in relation to ageing. Moreover, there is a lack of comparative studies of TAC activity in different honeybee body fluids like workers' haemolymph and drone seminal plasma. Antioxidant protection of worker bee larvae was influenced by exposure to pesticides (Derecka et al. 2013). The effects of pesticide exposure on protection against ROS in workers and forager bees are unknown. The objective of this study was to analyse the TAC of honeybee haemolymph in relation to age and exposure to pesticides. Moreover, the TAC measurements were applied for the first time to drones' seminal plasma. This information is important for better understanding the mechanism of sperm protection against oxidative stress.

\section{MATERIAL AND METHODS}

\subsection{Animals and sampling}

\subsubsection{Honeybee workers and haemolymph collection}

The experiment was done during the beekeeping season (June-August 2014) and used workers and drones reared in honeybee (Apis mellifera carnica) colonies kept in an apiary near Olsztyn, Poland (lat. 53.745117, long. 20.449361). We used colonies occupying two supers of Wielkopolski hives with $360 \times 260 \mathrm{~mm}$ frames of a type commonly used in Poland. Each colony contained a 2-year-old queen, naturally mated, about 40,000 workers and 20 wax combs.

Twelve colonies were randomly assigned to three experimental groups. Colonies from group BE (control group) were given food free from imidacloprid (IMD, Bayer Health Care AG, Leverkusen, Germany), while the food administered to colonies from group BE-5 and BE-200 was contaminated with 5 and 200 ppb of IMD, respectively. The bees were fed with sugar syrup [ratio sugar to water 5:3 $(w / w)]$ and pollen pastry made from fresh pollen loads and inverted syrup API-Fortune HF 1575 (ICKO, Bollène, France) in the ratio 2.5:1.4 (w/ $w$ ). The control colonies were given $5.66 \pm 0.12 \mathrm{~kg}$ of syrup for a total period of 65 days and IMD groups consumed $5.42 \pm 0.13 \mathrm{~kg}$ and $5.31 \pm 0.9 \mathrm{~kg}$ for 5 and $200 \mathrm{ppb}$ doses, respectively. The amounts of consumed syrup were not significantly different for the examined groups $(p=0.085)$. The syrup was given in 5-day intervals in the feeders which allow only a few bees parallel access to the syrup. Every 5 days, we changed the syrup, for bees which did not take all of the $0.5-\mathrm{kg}$ portion. Syrup intake was measured by weighting. The pollen pastry was given in two portions of $0.15 \mathrm{~kg}$ each at an interval of 35 days. After that, the second portion $(0.15 \mathrm{~kg})$ was given and eaten by bees to the end of 
the experiment. The pollen pastry was taken by bees very slowly. The hive weight trend was not controlled. Hives were located in poor nectar fields, and collected nectar and pollen were used for the production of honey and bee bread used exclusively for own needs of bees.

Queens in all colonies were caged on worker combs in a three-comb isolator 4 weeks after the start of feeding. After $24 \mathrm{~h}$, the queens were released and the combs with eggs were isolated to prevent the queen from laying eggs on them again. The brooded cells were sealed on the 9th day after egg-laying; after the next 11 days, the combs with brood were tagged and then placed in isolators which were incubated at $34.5^{\circ} \mathrm{C}$. During the next $24 \mathrm{~h}$, the time of worker emergence was checked at 4-h intervals. Fifty workers from each colony were kept in cages $(130 \times 115 \times 70 \mathrm{~mm})$ supplied with Apifonda candy ad libitum (Südzucker, Ochsenfurt, Germany). After $4 \mathrm{~h}$, haemolymph was collected. Another 950 workers were marked with different colours and put back into the colony for haemolymph analysis at the ages of 15 and 30 days.

Haemolymph was collected from the dorsal vessels after a puncture of the abdominal intersegmental membrane between the third and fourth tergites. Approximately $4 \mu \mathrm{L}$ of transparent haemolymph was collected from each individual. The haemolymph was transferred from the capillary tube to a microcentrifuge tube, spun down and diluted two times with assay buffer provided in a commercial antioxidant assay kit (SigmaAldrich, Saint Louis, MO, USA). The samples were immediately frozen at $-26{ }^{\circ} \mathrm{C}$ or stored on ice for 10 , 60 or $90 \mathrm{~min}$. TAC was measured in fresh, stored and frozen haemolymph of honeybees free from IMD at age 15 to 30 days. For the assessment of the effects of IMD and age on the TAC activity, haemolymph was diluted two times with assay buffer (see above) and immediately frozen at $-26^{\circ} \mathrm{C}$. TAC activity was measured after 2 days of storage at $-26^{\circ} \mathrm{C}$.

\subsubsection{Honeybee males and semen collection}

Queens in control colonies were caged on a drone comb in a three-comb isolator 4 weeks after the start of feeding. After $24 \mathrm{~h}$, the queens were released and the combs with eggs were isolated to prevent the queen from laying eggs on them again. The brooded cells were sealed on the 23rd day after egg-laying; the combs with brood were tagged and then placed in isolators which were incubated at $34.5^{\circ} \mathrm{C}$. During the next $24 \mathrm{~h}$, the time of drone emergence was checked at 6-h intervals.

The emerged drones were weighed and marked with colour. Next, they were put in a lower super in the bee colonies where they remained until the end of the study. The supers were isolated from the bottom and the top with a queen excluder which prevented the drones but not workers from passing through. The drones stayed in the colonies until they were 15 days old. Three to four hours before semen collection, the drones were caught and transported to the laboratory together with workers in cages $(130 \times 115 \times 70 \mathrm{~mm})$ supplied with Apifonda candy ad libitum.

Male semen was collected by provoking the organ to evert by slightly bending the thorax and pressing it with the fingers, following the method described by Cobey et al. (2013). Each male provided approximately $1 \mu \mathrm{L}$ of ejaculate. A total of five independent biological samples of $100 \mu \mathrm{L}$ of ejaculate was used for measurement of TAC. Immediately after collection, each sample was centrifuged for $20 \mathrm{~min}$ at $16,000 \times \mathrm{g}$ at $4{ }^{\circ} \mathrm{C}$ to separate sperm from seminal plasma. Each sample was divided into two parts. One was stored on ice and the second was immediately frozen at $-26^{\circ} \mathrm{C}$. After $20 \mathrm{~min}$, TAC was measured in fresh and frozen seminal plasma.

\subsection{Measurement of IMD, 5-hydroxy- imidacloprid and olefin concentration in honey, bee bread and honeybee workers' bodies}

Samples of honey (10 g from each colony), bee bread ( $5 \mathrm{~g}$ from each colony), and workers (53 to 123 workers from each colony) were analysed for residual levels of IMD and its major metabolites (5-hydroxyimidacloprid and olefin). Moreover, the stability of the IMD in the syrup and pastry was analysed after 3 months of diet preparation. The sample preparation procedure, calibration standards and residue analysis using liquid chromatography-tandem mass spectrometry were performed according to the method protocol described by Pohorecka et al. (2012).

\subsection{Measurement of TAC and protein concentrations}

TAC was determined using a commercial antioxidant assay kit (Sigma-Aldrich). Absorbance was read at $405 \mathrm{~nm}$ using a Synergy H1 microplate reader (BioTek 
Instruments, Inc., Winooski, VT, USA). For this assay, we used $10 \mu \mathrm{L}$ of $20 \times$ diluted haemolymph or $10 \times$ diluted seminal plasma. TAC values of samples were expressed as an equivalent of the millimole concentration of a ( \pm )-6-hydroxy-2,5,7,8-tetramethylchromane-2carboxylic acid (Trolox) solution. A Trolox standard curve was prepared for the assay using a range of $0.00-0.42 \mathrm{mM}$.

Protein concentration was measured using the method of Lowry et al. (1951). Absorbance was measured at $750 \mathrm{~nm}$ using a Spekol 11 spectrophotometer (Carl Zeiss, Jena, Germany). Bovine albumin was used as the standard. The protein concentration was measured in honeybee haemolymph free from IMD at the ages of 1 and 30 days.

\subsection{Statistical analysis}

$t$ tests were used to compare TAC activity in haemolymph and seminal plasma, and to test the effect of honeybee age on protein concentration in haemolymph. A one-way ANOVA with Tukey test was used to test the effects of storage and freezing of haemolymph and the age of honeybees on TAC activity in haemolymph and syrup intake. The effect of age and IMD on TAC activity in haemolymph was analysed using a two-way ANOVA. Differences among means were determined by LSD tests. The differences were considered significant at $P \leq 0.05$. Statistica (Version 9.0, 2007, StatSoft, Inc., Tulsa, OK, USA) and GraphPad Prism (GraphPad Software Inc, San Diego, CA, USA) software were used for statistical calculations.

\section{RESULTS}

\subsection{Concentration and degradation of imidacloprid to 5-hydroxy- imidacloprid and olefin in honey, bee bread and honeybee workers' bodies}

After supplementation of honeybee diet with $5 \mathrm{ppb}$ of IMD, IMD was observed only in honey. After supplementation with $200 \mathrm{ppb}$, IMD was observed in honey, bee bread and workers' bodies (Table I). Moreover, the degradation of IMD and

Table I. Concentration of IMD, 5-hydroxy-imidacloprid and olefin concentration in honey, bee bread and honeybee workers' bodies.

\begin{tabular}{|c|c|c|c|c|}
\hline \multirow[t]{2}{*}{ IMD dose (ppb) } & \multirow{2}{*}{$\begin{array}{l}\text { Honey } \\
\mathrm{ng} / \mathrm{g}\end{array}$} & \multirow{2}{*}{$\begin{array}{l}\text { Beebread } \\
(\mathrm{ng} / \mathrm{g})\end{array}$} & \multicolumn{2}{|l|}{ Workers $^{\mathrm{a}}$} \\
\hline & & & (ng/g) & (ng/bee) \\
\hline \multicolumn{5}{|l|}{ IMD concentration } \\
\hline 0 & nd & nd & nd & nd \\
\hline 5 & $2.30 \pm 0.79$ & nd & nd & nd \\
\hline 200 & $66.67 \pm 11.30$ & $8.10 \pm 2.20$ & $3.77 \pm 4.12$ & $0.30 \pm 0.34$ \\
\hline \multicolumn{5}{|l|}{ IMD metabolites } \\
\hline \multicolumn{5}{|c|}{ 5-hydroxy-imidacloprid } \\
\hline 0 & nd & nd & nd & nd \\
\hline 5 & nd & nd & nd & nd \\
\hline 200 & nd & nd & $1.83 \pm 0.40$ & $0.13 \pm 0.01$ \\
\hline \multicolumn{5}{|l|}{ Olefin } \\
\hline 0 & nd & nd & nd & nd \\
\hline 5 & nd & nd & nd & nd \\
\hline 200 & nd & nd & $2.33 \pm 0.47$ & $0.16 \pm 0.02$ \\
\hline
\end{tabular}

Data represent mean $\pm \mathrm{SD}$

Nd not detected

${ }^{\text {a }}$ Workers at age $1-10$ days 


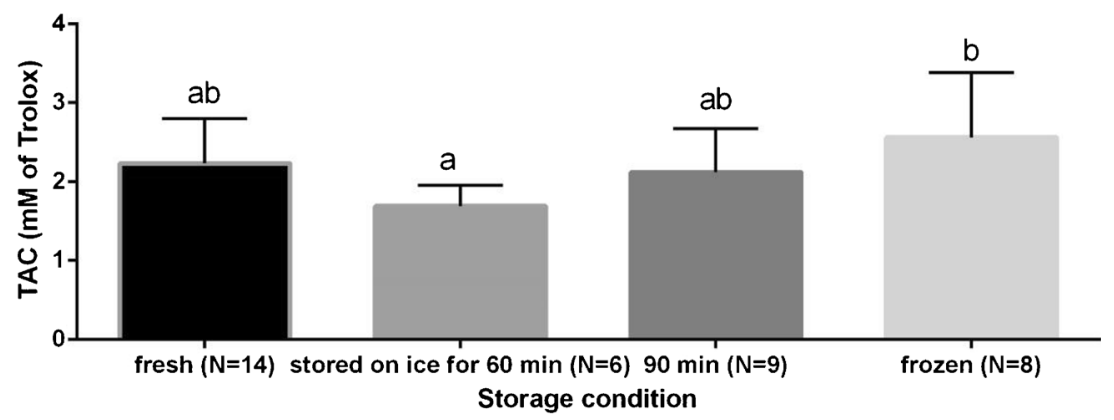

Figure 1. The effects of storage conditions on TAC activity in haemolymph. Data represent mean values \pm SD. Different letters indicate statistical significance at $P \leq 0.05$ indicated by ANOVA with Tukey test. $N=$ biological replicate (haemolymph from individual bees free from IMD at age 15 to 30 days).

the appearance of 5-hydroxy-imidacloprid and olefin were observed only in honeybee bodies (Table I). The stability of the IMD in the syrup and pastry was analysed after 3 months of storage and was determined to be 4.1 and $198 \mathrm{ppb}$ in groups of 5 and $200 \mathrm{ppb}$, respectively.

\subsection{TAC in body fluid of honeybees}

TAC of honeybee haemolymph varied from 1.16 to $3.92 \mathrm{mM}$ of Trolox. Neither storage nor freezing affected TAC of haemolymph (Figure 1).

TAC of seminal plasma ranged from 1.18 to $1.56 \mathrm{mM}$ of Trolox. Freezing did not affect TAC of seminal plasma.

Haemolymph was characterised by higher TAC than seminal plasma (Figure 2).

\subsection{Differences in TAC in haemolymph in relation to age and IMD treatment}

TAC increased with age of bee. TAC of haemolymph of bees at 30 days was greater than for 1-day-old bees (Figure 3).

TAC in haemolymph of 1-day-old bees was lower in bees fed 5 ppb IMD compared with controls (Figure 4, Table II). Increasing the IMD dose to $200 \mathrm{ppb}$ did not result in further reduction in TAC (Figure 4).

No changes in TAC activity were observed in haemolymph of 30-day-old bees with IMD treatment (Figure 4, Table II).

\subsection{Protein concentration of haemolymph of bees at age 1 and 30 days}

Four times higher protein concentration was found in haemolymph of bees at 30 days than in 1-day-old bees (Figure 5).

\section{DISCUSSION}

The present study demonstrates that TAC can be measured in honeybee haemolymph and seminal plasma. Haemolymph was characterised by higher TAC than seminal plasma. Neither storage nor freezing affected measurement of TAC of haemolymph and seminal plasma. TAC and protein concentration increased with age of bees up to 30 days. Exposure to IMD decreased TAC of

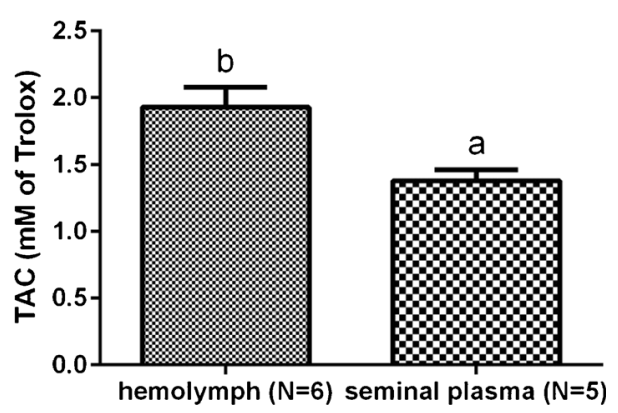

Figure 2. TAC in fresh haemolymph and seminal plasma. Data represent mean values \pm SD. Different letters indicate statistical significance at $P \leq 0.05$ indicated by $t$ test. $N=$ biological replicate (haemolymph from individual bees at age 15 to 30 days and pooled samples of seminal plasma of drones at age 14 to 18 days. Workers and drones were free from IMD). 


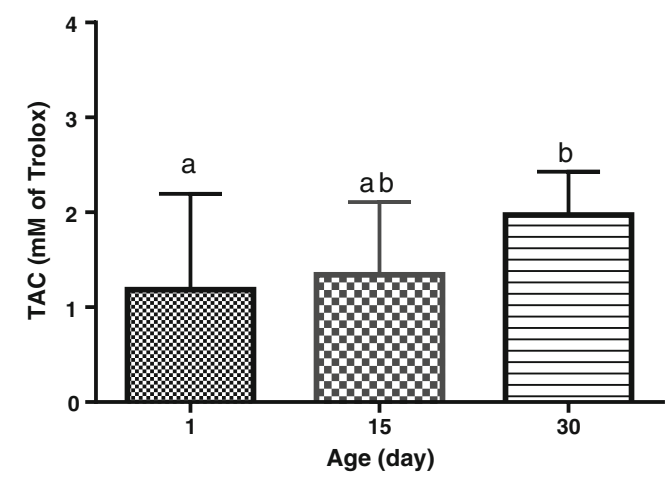

Figure 3. TAC of haemolymph in relation to the age of the honeybees. Data represent mean values \pm SD. Different letters indicate statistical significance at $P \leq 0.05$ indicated by ANOVA with Tukey test. $N=15$ samples of haemolymph from individual bees free from IMD.

haemolymph of 1-day-old bees but not 30-dayold bees.

To our knowledge, TAC has thus far been measured only in homogenates of whole brood/ pupae and honeybee extracts (Farjan et al. 2012, 2014) or body segments (whole abdomens of honeybee queen (Alaux et al. 2011), head and thorax of foragers and nurse (Williams et al. 2008). The values of TAC measurements in whole-body homogenate or segments are limited because the specific origin of antioxidant protection cannot be defined. We demonstrated TAC in haemolymph for the first time, extending our knowledge of total antioxidative protection in honeybee haemolymph (Weirich et al. 2002).

To date, activity of SOD, CAT and GST has been found in honeybee haemolymph (Weirich et al. 2002). Activity of antioxidant enzymes is low and the honeybee genome is characterised by low number of genes coding for antioxidative protein (Corona and Robinson 2006), which contributes to limited defence against ROS in comparison to other insects. This suggests that measurement of the activity of individual enzymes has limited usefulness for evaluation of antioxidative protection in honeybee haemolymph. Therefore, measurements of TAC allow evaluation of complete antioxidant protection in haemolymph (both enzymatic and non-enzymatic). Further studies are necessary to carefully evaluate the participation of non-enzymatic and enzymatic compounds in TAC to identify the mechanisms of antioxidative protection in honeybees.

This is the first report describing TAC in drone seminal plasma. To date, enzymatic compounds of antioxidative protection consisting of SOD, GSH and catalase have been studied in detail in drone reproductive tissue and semen, and spermathecae of queens (Weirich et al. 2002; Collins et al. 2004, 2006). The substantial activities of all three enzymes in spermathecae of mated queens suggest their involvement in the long-term protection of the spermatozoa from oxidative stress (Weirich et al. 2002). Males showed higher transcript levels and protein activity for these three antioxidants than did females in both somatic and reproductive tissue (Weirich et al. 2002; Collins et al. 2004). In our study, higher TAC was observed in worker bee haemolymph than in seminal plasma. This suggests that TAC of honeybee haemolymph may consist of higher non-

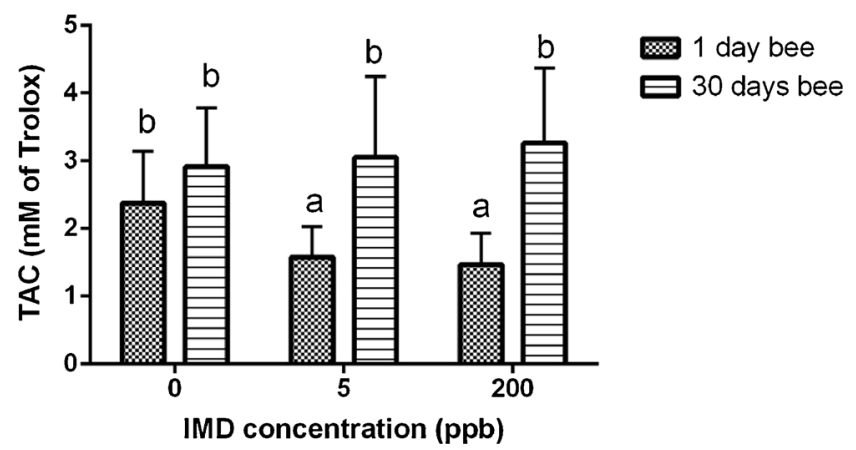

Figure 4. TAC of haemolymph in relation to age and IMD exposure. Data represent mean values \pm SD. Different letters indicate statistical significance at $P \leq 0.05$ between groups indicated by two-way ANOVA with LSD test. $N=$ 15 samples of haemolymph from individual bees. 
Table II. TAC of haemolymph in relation to age and exposure to pesticide.

\begin{tabular}{lll}
\hline Age & $\begin{array}{l}\text { IMD dose } \\
(\mathrm{ppb})\end{array}$ & $\begin{array}{l}\text { TAC } \\
(\mathrm{mM} \text { of Trolox })\end{array}$ \\
\hline 1 day & 0 & $2.37 \mathrm{~b}$ \\
& 5 & $1.57 \mathrm{a}$ \\
& 200 & $1.46 \mathrm{a}$ \\
30 days & 0 & $2.91 \mathrm{~b}$ \\
& 5 & $3.05 \mathrm{~b}$ \\
Age of bee & 200 & $3.26 \mathrm{~b}$ \\
& 1 days & $1.80 \mathrm{z}$ \\
IMD dose & 30 days & $3.07 \mathrm{y}$ \\
& $0 \mathrm{ppb}$ & 2.64 \\
& $5 \mathrm{ppb}$ & 2.31 \\
SD & $200 \mathrm{ppb}$ & 2.36 \\
$P$ value & & 1.09 \\
Age & & $<0.0001$ \\
IMD dose & & 0.277 \\
Age $\times$ IMD dose & & 0.015 \\
\hline
\end{tabular}

Means within a column with different letters (a, b) are significantly different $(P \leq 0.05)$. Letters indicate statistical significance in relation to the age of the honeybees

Means within a column with different letters $(\mathrm{z}, \mathrm{y})$ are significantly different $(P \leq 0.05)$. Letters indicate statistical significance in relation to IMD exposure

enzymatic antioxidant concentrations than seminal plasma. This suggestion is supported by the

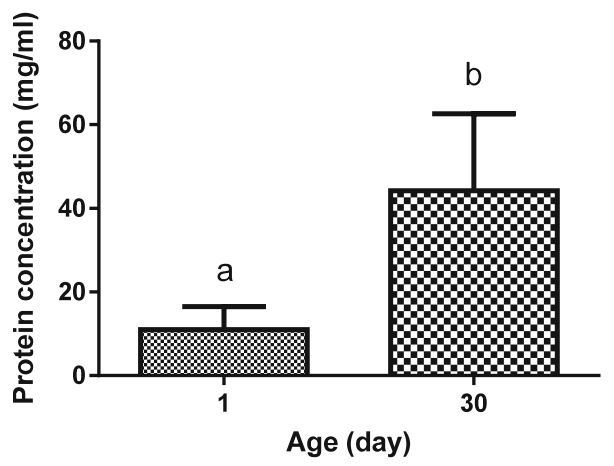

Figure 5. Protein concentration of haemolymph in relation to the age of the honeybees. Data represent mean values \pm SD. Different letters indicate statistical significance at $P \leq 0.05$ indicated by $t$ test. $N=15$ individual samples of haemolymph from individual bees free from IMD. study of Farjan et al. (2014) who demonstrated higher TAC levels in parasitised honeybee worker broods after supplementation of diet with vitamin C. However, it should be stressed that this effect was not observed in healthy broods (Farjan et al. 2012). Further studies are necessary to (i) compare TAC in haemolymph of drones and honeybee workers and (ii) quantify non-enzymatic and enzymatic compounds of haemolymph and seminal TAC.

In our study, we found an increase of TAC in haemolymph with honeybee ageing up to 30 days. The increased TAC in haemolymph of bees at 30 days observed in our study concords with existing knowledge concerning antioxidative protection in honeybees. Generally, an increase in ROS generation and enhancement of antioxidant protection is associated with ageing and transition of worker bees to foraging (Johnson and Carey 2014). The higher antioxidant protection in foragers may result from an increased need for detoxification of ROS produced during flight and contact with various pollutants. Increased values of TAC have been found in young foragers' flight muscles, whereas older foragers could no longer elevate flight muscle antioxidants in response to flight (Williams et al. 2008). It is unknown at present if this variability may be reflected by TAC levels in haemolymph. Increased $\mathrm{Cu} / \mathrm{Zn}$ SOD content in thorax muscle cells and increased activity of CAT, GST and microsomal oxidase in the midgut of worker bees have been identified as components of the detoxification system (Jimenez and Gilliam 1996; Schippers et al. 2006). Our study suggests that enhancement of antioxidant protection in bees at 30 days might be connected with higher levels of antioxidants in honeybee haemolymph. Therefore, measurement of TAC in haemolymph appears to be a valuable parameter for further studies of the mechanism of ageing in honeybees.

There are many conflicting data regarding the effect of age on the antioxidant activity of animals. In mammals, increases, decreases or no differences in antioxidant enzyme activities were found in different species, ages and organs (Rao et al. 1990; Sohal et al. 1990; Gündüz et al. 2004; Kakarla et al. 2005; Vaanholt et al. 2008). In our study, we have found an increase in the 
antioxidant capacity and protein concentration of honeybee haemolymph up to 30 days. These results are in agreement with recently published studies by Strachecka et al. (2014, 2015). These authors showed a steady increase of antioxidant enzymes (SOD, GPx, CAT, GST) and ferric reducing antioxidant potential in haemolymph of honeybees until 30 days. This agrees with our data and suggests a high antioxidative potential of aged forager bees. However, a decrease in antioxidant activity was observed in the haemolymph of foragers older than 30 days (Strachecka et al. 2014, 2015). Therefore, it can be suggested that for honeybees, higher antioxidant activity is characteristic for the early stage of ageing, which reflects the foraging activity of bees in this period and usefulness for bee community. Maintaining high levels of antioxidant enzyme activity in old age has been described in animals and is related to the diminished accumulation of damaged proteins and an increase in cell survival, delayed ageing and the onset of age-associated diseases that finally can extend the lifespan (Melov et al. 2000; Vaanholt et al. 2008).

Comparative analysis of the protein concentration in honeybee haemolymph seems to be problematic due to the high variability of reported data. In the available literature, the protein concentration of haemolymph ranges from 10 to $50 \mathrm{mg} / \mathrm{mL}$ (Fluri et al. 1982; Michelette and Engels 1995) or is as low as 0.2 to $1.6 \mathrm{mg} / \mathrm{mL}$ (Eckholm et al. 2015; Strachecka et al. 2014, 2015). Moreover, the protein concentration of honeybees fluctuates according to the postembryonic stages, age of the bee, season (summer and winter) and diets (Fluri et al. 1982; Michelette and Engels 1995; De Jong et al. 2009; Eckholm et al. 2015). A decrease (Fluri et al. 1982; Eckholm et al. 2015) or increase (Strachecka et al. 2014, 2015) in protein concentration was reported for the foragers (older bees). The increase in protein concentration in honeybee haemolymph from 1 day until 30 days observed in our work agrees with recently published data by Strachecka et al. (2014; 2015). At present, it is difficult to understand the mechanism of protein concentration changes in honeybee haemolymph. Therefore, further detailed studies are needed.

It should be underlined that within the conditions of our experimental design, honeybees were free to forage and were not constricted to feed exclusively on the provided food with 5 and $200 \mathrm{ppb}$ of IMD. It was our deliberate intention because we aimed to study the influence of IMD doses of imidacloprid on bees in free-flying colonies. Most of the IMD was probably not consumed but stored as honey and bee bread. Therefore, it was difficult to determine exactly how much of the IMD was taken by the bees. Nevertheless, our results clearly indicated that supplementation of syrup and pollen pastry with IMD resulted in the transfer of IMD to both food and honeybees' bodies. Moreover, we have demonstrated that IMD can be metabolised in honeybee bodies to derivatives (5-hydroxy-imidacloprid and olefin), which agrees with the data of Suchail et al. (2004). Those results clearly suggest that honey and bee bread can be secondary sources of IMD for bees. Further studies are necessary to evaluate the detailed circulation of IMD within a hive and its effect on TAC during the development of bees.

There is at present limited information on the effects of chronic exposure to insecticide on antioxidant protection of honeybees. The key mechanism of pesticides' cytotoxicity may be linked to their pro-oxidative potential, including damage by free radical oxidation of cellular components such as membrane lipids, protein and DNA and antioxidants may attenuate the pesticides-induced cell toxicity (Ilboudoa et al. 2014; Poljšak and Fink 2014). Recently, Derecka et al. (2013) demonstrated overexpression of the immune-regulated catalase gene of honeybee larvae after exposure to low levels of insecticides. In our study, we observed decreased TAC level in the haemolymph of 1-day-old honeybees exposed to IMD, which suggests that exposure to insecticide leads to decrease in antioxidant protection of 1-day-old honeybees. Presumably, overexpression of the CAT gene found in larvae (Derecka et al. 2013) did not effectively compensate antioxidant protection in 1-day-old honeybees. The effect of pesticides on antioxidant protection of honeybees has been demonstrated in larvae from open cells (Derecka et al. 2013) and was observed for 1-day-old honeybees (our study), which suggest that honeybees are susceptible to the toxic effect of pesticides during brood development (approximately 21 days) and emergence. In contrast to 1-day-old 
bees, TAC was no different in bees exposed to IMD compared with controls at 30 days. This suggests that older bees with higher antioxidant protection are less susceptible to the toxic effect of IMD. Our results strongly suggest that age of bees, and presumably forage, is an important factor influencing the toxic effect of pesticide. The toxic effect of pesticide seems to be especially dangerous in the early stage of life of honeybees.

In conclusion, we have demonstrated for the first time that TAC can be measured in honeybee body fluids. Antioxidant protection of honeybees is related to age and may be disturbed by exposure to IMD. Older bees with higher antioxidant protection seem to be less susceptible to the toxic effect of IMD. Toxic effects of pesticide seem to be especially dangerous in early life stages of honeybees.

\section{ACKNOWLEDGMENTS}

This work was funded by the Institute of Animal Reproduction and Food Research and the University of Warmia and Mazury in Olsztyn. The authors would like to thank the two anonymous reviewers for their valuable comments and suggestions.

Capacité antioxydante totale de l'hémolymphe de l'abeille en relation avec l'âge et l'exposition aux pesticides, et comparaison avec la capacité antioxydante du plasma séminal

Apis mellifera / Hymenoptera / stress oxydatif / vieillissement / effet de l'âge

Gesamtantioxidanzkapazität der Bienenhämolymphe in Bezug auf Alter und Pestizidexposition, und ein Vergleich mit der Antioxidanzkapazität von Seminalplasma

Apis mellifera / Gesamtantioxidanzkapazität / Hämolymphe / Alterung / Pestizide

\section{REFERENCES}

Alaux, C., Folschweiller, M., McDonnell, C., Beslay, D., Cousin, M., Dussaubat, C., Brunet, J.L., Le Conte, Y. (2011) Pathological effects of the microsporidium Nosema ceranae on honey bee queen physiology (Apis mellifera ). J. Invertebr. Pathol. 106(3), 380-385
Cobey, S.W., Tarpy, D.R., Woyke, J. (2013) Standard methods for instrumental insemination of Apis mellifera queens. J. Apic. Res. 52 (4), 1-18

Collins, A.M., Williams, V., Evans, J.D. (2004) Sperm storage and antioxidative enzyme expression in the honey bee, Apis mellifera . Insect Mol. Biol. 13 (2), 141-146

Collins, A.M., Caperna, T.J., Williams, V., Garrett, W.M., Evans, J.D. (2006) Proteomic analyses of male contributions to honey bee sperm storage and mating. Insect Mol. Biol. 15(5), 541-549

Colven, R.M., Pinnell, S.R. (1996) Topical vitamin C in aging. Clin. Dermatol. 14 (2), 227-234

Corona, M., Robinson, G.E. (2006) Genes of the antioxidant system of the honey bee: annotation and phylogeny. Insect Mol. Biol. 15(5), 687-701

De Jong, D., da Silva, E.J., Kevan, P.G., Atkinson, J.L. (2009) Pollen substitutes increase honey bee haemolymph protein levels as much as or more than does pollen. J. Apic. Res. 48(1), 34-37

Derecka, K., Blythe, M.J., Malla, S., Genereux, D.P., Guffanti, A., et al. (2013) Transient exposure to low levels of insecticide affects metabolic networks of honeybee larvae. PLoS One 8(7), 1-11

Eckholm, B.J., Huang, M.H., Anderson, K.E., Mott, B.M., Hoffman, G.D. (2015) Honey bee (Apis mellifera) intracolonial genetic diversity influences worker nutritional status. Apidologie 46 (2), 150-163

Farjan, M., Dmitryjuk, M., Lipinski, Z., Biernat-Lopienska, E., Zoltowska, K. (2012) Supplementation of the honey bee diet with vitamin $\mathrm{C}$ : The effect on the antioxidative system of Apis mellifera carnica brood at different stages. J. Apic. Res. 51 (3), 263-270

Farjan, M., Łopieńska-Biernat, E., Lipiński, Z., Dmitryjuk, M., Źołtowska, K. (2014) Supplementing with vitamin $\mathrm{C}$ the diet of honeybees (Apis mellifera carnica) parasitized with Varroa destructor: effects on antioxidative status. Parasitology 141 (6), 770-776

Felton, G.W. (1995) Antioxidant defenses of invertebrates and vertebrates. In: Ahmad, S. (ed.) Oxidative stress and antioxidant defenses in biology, pp. 356-434. Chapman \& Hall, New York

Felton, G.W., Summers, C.B. (1995) Antioxidant systems in insects. Arch. Insect Biochem. Physiol. 29 (2), 187-197

Fluri, P., Lüscher, M., Wille, H., Gerig, L. (1982) Changes in weight of the pharyngeal gland and haemolymph titres of juvenile hormone, protein and vitellogenin in worker honey bees. J. Insect Physiol. 28(1), 61-68

Gündüz, F., Sentürk, U.K., Kuru, O., Aktekin, B., Aktekin, M.R. (2004) The effect of one year's swimming exercise on oxidant stress and antioxidant capacity in aged rats. Physiol. Res. 53 (2), 171-176

Ilboudoa, S., Fouchea, E., Rizzatia, V., Toéb, A.M., GametPayrastrea, L., Guissoub, P.I. (2014) In vitro impact of five pesticides alone or in combination on human intestinal cell line Caco-2. Toxicol. Rep. 1, 474-489

Jimenez, D.R., Gilliam, M. (1996) Peroxisomal enzymes in the honey bee midgut. Arch. Insect Biochem. Physiol. 31 (1), 87-103 
Johnson, B., Carey, J.R. (2014) Hierarchy and connectedness as determinants of health and longevity in social insects. In: Weinstein, M., Lane, M.A. (eds.) Sociality, hierarchy, health: comparative biodemography: a collection of papers, pp. 269-295. National Academies Press, Washington

Kakarla, P., Vadluri, G., Reddy Kesireddy, S. (2005) Response of hepatic antioxidant system to exercise training in aging female rat. J. Exp. Zool. A. Comp. Exp. Biol. 303 (3), 203-208

Krishnan, N., Kodrík, D., Kłudkiewicz, B., Sehnal, F. (2009) Glutathione-ascorbic acid redox cycle and thioredoxin reductase activity in the digestive tract of Leptinotarsa decemlineata (Say). Insect Biochem. Mol. Biol. 39 (3), 180-188

Lowry, O.H., Rosebrough, N.J., Farr, A.L., Randall, R.J. (1951) Protein measurement with the Folin phenol reagent. J. Biol. Chem. 193, 265-275

Melov, S., Ravenscroft, J., Malik, S., Gill, M.S., Walker, D.W., et al. (2000) Extension of life-span with superoxide dismutase/catalase mimetics. Science 289 (5484), 1567-1569

Michelette, E., Engels, W. (1995) Concentration of hemolymph proteins during postembryonic worker development of Africanized honey bees in Brazil and Carniolans in Europe. Apidologie 26 (2), 101-108

Michiels, C., Raes, M., Toussaint, O., Remacle, J. (1994) Importance of Se-glutathione peroxidase, catalase, and $\mathrm{Cu} / \mathrm{Zn}$-SOD for cell survival against oxidative stress. Free Radic. Biol. Med. 17 (3), 235-248

Pardini, R.S. (1995) Toxicity of oxygen from naturally occurring redox-active pro-oxidants. Arch. Insect Biochem. Physiol. 29(2), 101-118

Pohorecka, K., Skubida, P., Miszczak, A., Semkiw, P., Sikorski, P. (2012) Residues of neonicotinoid insecticides in bee collected plant materials from oilseed rape crops and their effect on bee colonies. J. Apic. Sci. 56(2), 115-134

Poljšak, B., Fink, R. (2014) The protective role of antioxidants in the defence against ROS/RNS-mediated environmental pollution oxidative medicine and cellular longevity. Oxidative Med. Cell. Longev. . doi:10.1155/ 2014/671539

Rao, G., Xia, E., Richardson, A. (1990) Effect of age on the expression of antioxidant enzymes in male Fischer F344 rats. Mech. Ageing Dev. 53 (1), 49-60

Schippers, M.P., Dukas, R., Smith, R.W., Wang, J., Smolen, K., McClelland, G.B. (2006) Lifetime performance in foraging honeybees: behaviour and physiology. J. Exp. Biol. 209, 3828-3836

Sohal, R.S., Arnold, L.A., Sohal, B.H. (1990) Age-related changes in antioxidant enzymes and prooxidant generation in tissues of the rat with special reference to parameters in two insect species. Free Radic. Biol. Med. 9 (6), 495-500

Strachecka, A., Olszewski, K., Paleolog, J., Borsuk, G., Bajda, M., Krauze, M., Merska, M., Chobotow, J. (2014) Coenzyme Q10 treatments influence the lifespan and key biochemical resistance systems in the honeybee, Apis mellifera. Arch. Insect Biochem. Physiol. 86(3), 165-179

Strachecka, A.J., Olszewski, K., Paleolog, J. (2015) Curcumin stimulates biochemical mechanisms of Apis mellifera resistance and extends the apian life-span. J. Apic. Sci. 59 (1), 129-141

Suchail, S., Debrauwer, L., Belzunces, L.P. (2004) Metabolism of imidacloprid in Apis mellifera . Pest Manag. Sci. 60 (3), 291-296

Summers, C.B., Felton, G.W. (1993) Antioxidant role of dehydroascorbic acid reductase in insects. Biochim. Biophys. Acta 1156 (2), 235-238

Vaanholt, L.M., Speakman, J.R., Garland Jr., T., Lobley, G.E., Visser, G.H. (2008) Protein synthesis and antioxidant capacity in aging mice: effects of long-term voluntary exercise. Physiol. Biochem. Zool. 81 (2), 148-157

Weirich, G.F., Collins, A.M., Williams, W.P. (2002) Antioxidant enzymes in the honey bee, Apis mellifera. Apidologie 33 (1), 3-14

Williams, J.B., Roberts, S.P., Elekonich, M.M. (2008) Age and natural metabolically-intensive behavior affect oxidative stress and antioxidant mechanisms. Exp. Gerontol. 43 (6), 538-549 